\title{
An empirical investigation on the effects of spiritual leadership components on organizational learning capacity: A case study of Payame Noor University
}

\author{
Amir Hossein Amir Khani ${ }^{\mathrm{a}}$ and Hossein Sotudeh Arani ${ }^{\mathrm{b}^{*}}$
}

${ }^{a}$ Assistant Professor, Department of Economic ,Management and Accounting, Payame Noor University 19395-4697,Tehran, Iran ${ }^{b}$ Management Group, Payame Noor University, Tehran, Iran

\section{H R O N I C L E}

\section{Article history:}

Received January 18, 2013

Received in revised format

3 May 2013

Accepted 20 May 2013

Available online

May 252013

Keywords:

Spiritual leadership

Organizational learning capacity

Payame Noor University

\section{A B S T R A C T}

This paper presents an empirical investigation on the effects of spiritual leadership components on organizational learning capacity for a case study of Payame Noor University, Iran. The proposed study uses a standard questionnaire for measuring spirituality leadership proposed by Fry (2003) [Fry, L. W. (2003). Toward a theory of spiritual leadership. The leadership quarterly, 14(6), 693-727.] and for measuring the impact of organizational learning capacity, the proposed study uses another questionnaire proposed by Teo et al. (2006) [Teo, H. H., Wang, X., Wei, K. K., Sia, C. L., \& Lee, M. K. (2006). Organizational learning capacity and attitude toward complex technological innovations: an empirical study. Journal of the American Society for Information Science and Technology, 57(2), 264-279.]. The results of our survey have indicated that all components of spiritual leadership, except love and altruism as meaningful, influence spirituality leadership, significantly.

(C) 2013 Growing Science Ltd. All rights reserved.

\section{Introduction}

Leadership plays a key factor on the success of organizations and there are many studies, which have concentrated on different aspects of leadership (Maxwell, 2003; Senge, 2006; Schein, 2006). According to Fry (2003), a causal theory of spiritual leadership could be developed within an intrinsic motivation framework, which includes vision, hope/faith, and altruistic love, theories of workplace spirituality, and spiritual survival. The primary objective of spiritual leadership is to build vision and value congruence across the strategic, empowered team to foster better levels of organizational commitment and productivity. Fry (2003) investigated leadership as motivation to change motivationbased leadership theories and reported that the accelerating call for spirituality in the workplace, could explain the universal human requirement for spiritual survival through calling and membership. Fry (2003) argued that spiritual leadership theory is not only inclusive of other major extant

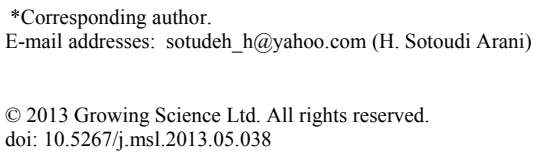


motivation-based theories of leadership, but also it could be more conceptually distinct, parsimonious, and less conceptually confounded.

Teo et al. (2006) detected four components of organizational learning capacity, namely, systems orientation, organizational climate for learning orientation, knowledge acquisition and utilization orientation, and information sharing and dissemination orientation. They used structural equation modeling analyses to give some insights about structure and dimensionality of these factors. They reported that the proposed four major dimensions could be associated with organizational learning capacity. Organizational learning capacity, as a higher-order factor, had a substantial effect on attitude towards organizational adoption of knowledge-intensive innovations. Kandemir and Hult (2005) concentrated on organizational learning and innovation in international joint ventures (IJVs). They presented a conceptual framework, which depicted the relationship among the parent organization(s)' climate, IJVs' organizational learning culture, innovativeness culture, innovation capacity and IJV performance.

Slater and Narver (1995) described the processes through which organizations could use new knowledge to improve performance. They proposed a set of organizational elements, which comprise the learning organization. Sanders et al. (2003) explored the spiritual dimensions of leadership by setting forth a theory where both integrated the transactional and transformational theories of leadership. They proposed that the transcendental theory of leadership could comprise of three dimensions of spirituality including consciousness, moral character, and faith, which include the managerial specifications of transactional theory and the charismatic characteristics of transformational theory to enhance leader effectiveness. They explained the hierarchical relationship, which exist between transcendental, transformational, and transactional theories of leadership and set forth several propositions associated with the development of spiritual dimensions as leaders develop along the hierarchical continuum.

Korac-Kakabadse et al. (2002) reviewed leadership praxis from the frames of wider spiritualties, links spirituality search with contemporary practices and surveyed the breadth of, and commonalities within, varied philosophic positions with regard to the spiritual search. According to Konz and Ryan (1999), spirituality in general, and in the workplace in particular, has become an essential areas of research during the past few years and many people tried to develop an existing methods such as balanced scorecard (BSC) method originally developed by Kaplan and Norton (1992, 1996, 2004).

Fry et al. (2010), for instance, offered the Spiritual Leadership BSC Business Model as a driver of employee well-being, organizational commitment and productivity, corporate social responsibility and, ultimately, financial performance, via its impact on internal processes, output quality, and customer satisfaction.

Škerlavaj et al. (2007) presented and examined a model of organizational performance improvement based on the effect of organizational learning culture. The concept of organizational learning culture (OLC) was described as a set of norms and values about the functioning of a firm. They implemented data from 203 Slovenian firms employing more than 50 people. The effect of OLC on organizational performance was examined via structural equation modeling (SEM) and the results indicated that OLC had a positive direct effect on all three perspectives of non-financial performance included in the model including performance from the employee, customer, and supplier perspectives. The impact of organizational learning culture on financial performance was still positive in this survey, but indirect, as expected.

Mollaabbasi et al. (2013) surveyed the relationship between emotional intelligence and organizational indifference through a commitment. The study first presented theoretical models over the investigation then six hypotheses were developed based on the conceptual model for this opinion. The 
results concluded that there were significant relationship between emotional intelligence and organizational indifference.

\section{The proposed study}

This paper presents an empirical investigation on the effects of spiritual leadership components on organizational learning capacity for a case study of Payame Noor University, Iran. The proposed study uses a standard questionnaire for measuring spirituality leadership proposed by Fry (2003) and for measuring the impact of organizational learning capacity, the proposed study uses another questionnaire proposed by Teo et al. (2006). Fig. 1 shows details of our proposed study,

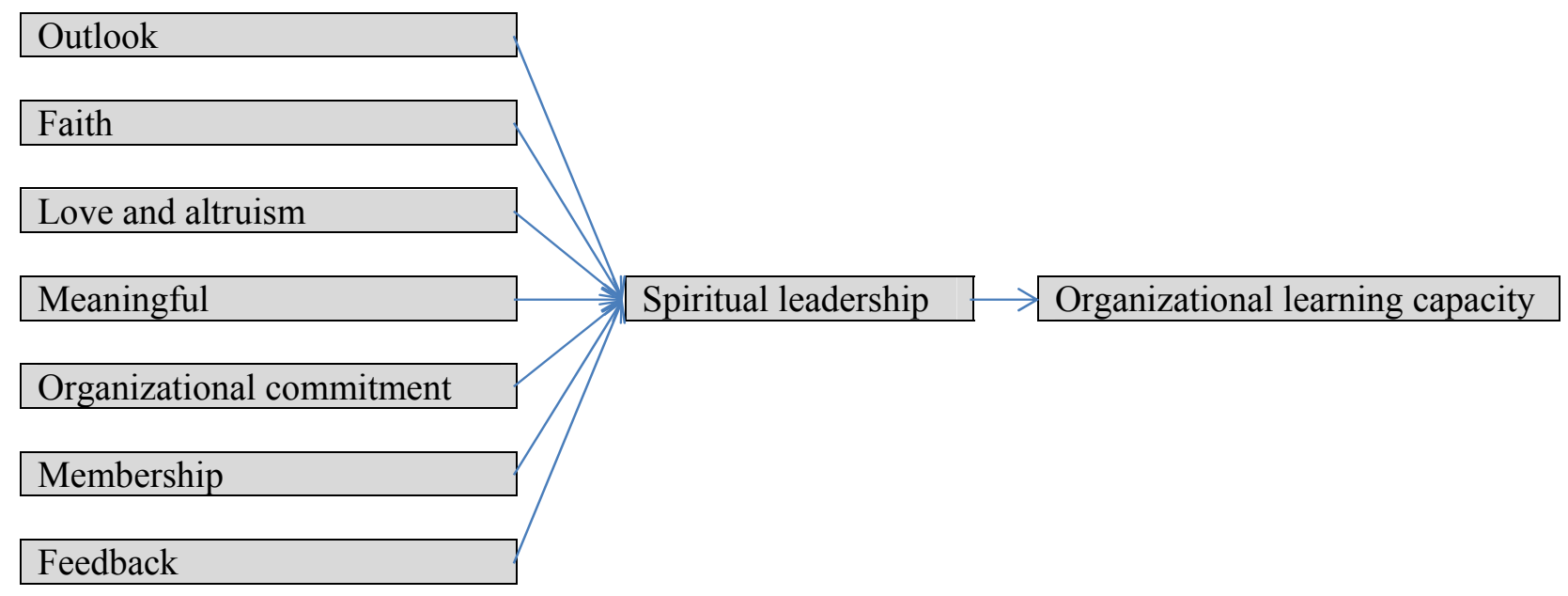

Fig. 1. The proposed study

Based on the structure of Fig. 1 we may present details of seven hypotheses as follows,

1. There is a relationship between organizational outlook and organizational learning capacity.

2. There is a relationship between organizational faith and organizational learning capacity.

3. There is a relationship between organizational love as well as altruism and organizational learning capacity.

4. There is a relationship between organizational meaningful and organizational learning capacity.

5. There is a relationship between organizational commitment and organizational learning capacity.

6. There is a relationship between organizational membership and organizational learning capacity.

7. There is a relationship between organizational feedbacks and organizational learning capacity.

In our study, the null hypothesis for all seven cases indicates that such relationship does not exist while the alternative hypothesis indicates that this relationship exists. The proposed study of this paper uses structural equation modeling (SEM) to test seven hypotheses and we present details of our findings in the next section.

\section{The results}

In this section, we present details of our findings on testing seven hypotheses based SEM technique. Fig. 2 shows the results of standard values. In addition, Fig. 3 shows details of t-student values associated with each relationship. Chi-Square value is equal 10029.30 with $\mathrm{df}=3131$. In addition, $\mathrm{p}$ - 
1550

value is equal to 0.0000 and RMSEA is equal to 0.084 , which is less than the reference value of 0.09 . These statistical observations confirm the overall program, which means that we can make judgment on all seven hypotheses. Based on the results of SEM, except two cases of love and altruism and meaningful, all other five hypotheses have been confirmed and we can conclude that organizational outlook, faith, commitment, membership and feedback influence organizational learning capability, significantly.

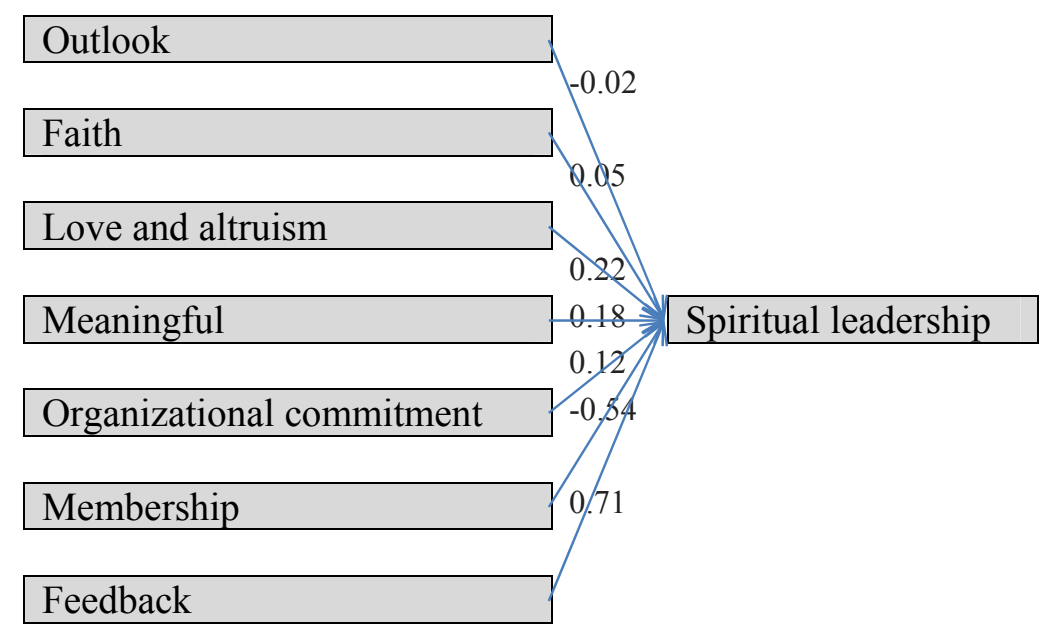

Fig. 2. The results of standard values associated with the implementation of SEM

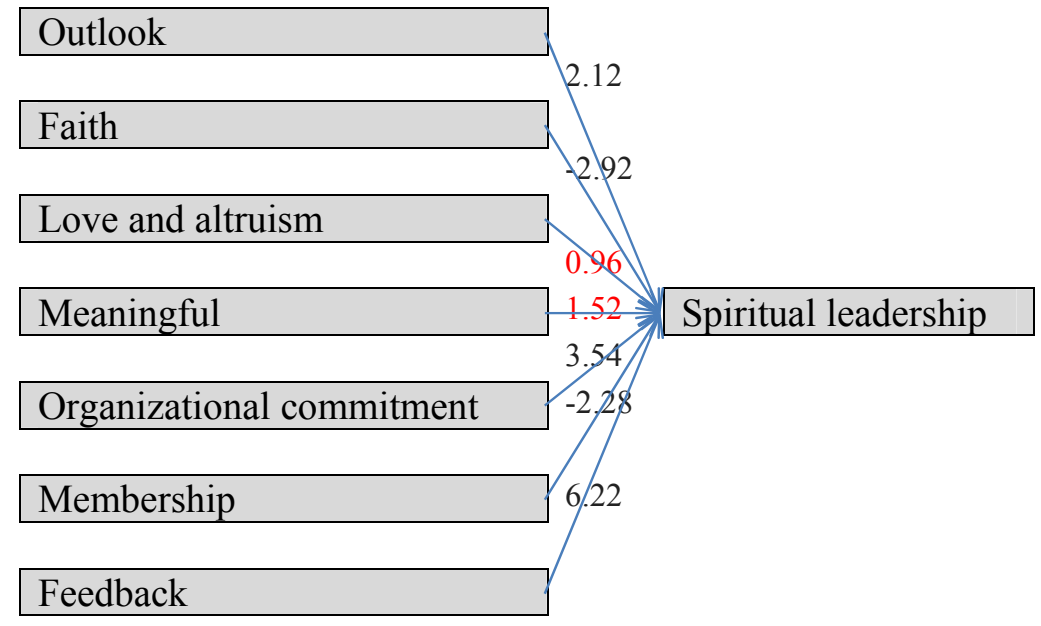

Fig. 3. The results of t-student values associated with the implementation of SEM

Table 1 summarizes the results of our survey on testing seven hypotheses of this survey.

\section{Table 1}

The results of testing seven hypotheses

\begin{tabular}{lcc}
\hline Path & $\beta$ & t-student \\
\hline Organizational outlook $\rightarrow$ organizational learning capability & -0.02 & $2.12^{* *}$ \\
Organizational faith $\rightarrow$ organizational learning capability & 0.05 & $2.92^{* *}$ \\
Organizational Love and altruism $\rightarrow$ organizational learning capability & 0.22 & $0.96^{*}$ \\
Organizational meaningful $\rightarrow$ organizational learning capability & 0.18 & $1.52^{*}$ \\
Organizational commitment $\rightarrow$ organizational learning capability & 0.12 & $3.54^{* *}$ \\
Organizational membership $\rightarrow$ organizational learning capability & -0.54 & $-2.29^{* *}$ \\
Organizational feedback $\rightarrow$ organizational learning capability & 0.71 & $6.22^{* *}$ \\
\hline ***
\end{tabular}

Organizational feedback $\rightarrow$ organizational learning capability

$*$ Level of significance $=0.05$ 
Based on the results of Table 1, organizational feedback maintains the biggest positive impact on organizational learning capability followed by organizational membership and commitment when the level of significance is one percent. The effects of Love and altruism and meaningful on organizational learning capability are significance only at $5 \%$ limit.

\section{Conclusion}

In this paper, we have performed an empirical investigation on the effects of different organization spirituality factors on organizational learning capability. The proposed study of the paper has adopted two standard questionnaires and using structural equation modeling, we have examined seven hypotheses. The results of our investigation have indicated that organizational feedback maintains the biggest positive impact on organizational learning capability followed by organizational membership and commitment when the level of significance is one percent. The effects of Love and altruism and meaningful on organizational learning capability are significance only at 5\% limit.

\section{Acknowledgment}

The authors would like to thank members of Payame Noor University for cordially helping us accomplish this survey.

\section{References}

Fry, L. W. (2003). Toward a theory of spiritual leadership. The leadership quarterly, 14(6), 693-727.

Fry, L. W., Matherly, L. L., \& Ouimet, J. R. (2010). The spiritual leadership balanced scorecard business model: the case of the Cordon Bleu-Tomasso Corporation. Journal of Management, Spirituality and Religion, 7(4), 283-314.

Kaplan, R.S. \& Norton, D.P. (1992). The balanced scorecard - measures that drive performance, Harvard Business Review, 70(1), 71-79.

Kaplan, R.S. and Norton, D.P. (1996). The balanced scorecard: translating strategy into action. Harvard Business School Press, Boston, MA.

Kaplan, R.S. \& Norton, D.P. (2004), Strategy maps: converting intangible assets into tangible outcomes, Harvard Business School Press, Boston, MA.

Kandemir, D., \& Hult, G. T. M. (2005). A conceptualization of an organizational learning culture in international joint ventures. Industrial marketing management, 34(5), 430-439.

Konz, G. N., \& Ryan, F. X. (1999). Maintaining an organizational spirituality: No easy task. Journal of Organizational Change Management, 12(3), 200-210.

Korac-Kakabadse, N., Kouzmin, A., \& Kakabadse, A. (2002). Spirituality and leadership praxis. Journal of managerial psychology, 17(3), 165-182.

Maxwell, T. P. (2003). Integral spirituality, deep science, and ecological awareness. Zygon®, 38(2), 257-276.

Mollaabbasi, H., Rezaeemanesh, B \& Sadaghiani, J. (2013). A study on relationship between emotional intelligence and organizational indifference through the organizational commitment: A case study of an Iranian firm. Management Science Letters, 3(5), 1327-1332.

Sanders, J. E., Hopkins, W. E., \& Geroy, G. D. (2003). From transactional to transcendental: Toward an integrated theory of leadership. Journal of Leadership \& Organizational Studies, 9(4), 21-31.

Schein, E. H. (2006). Organizational culture and leadership (Vol. 356). Jossey-bass.

Senge, P. M. (2006). The fifth discipline: The art \& practice of the learning organization. Crown Business.

Slater, S. F., \& Narver, J. C. (1995). Market orientation and the learning organization. The Journal of Marketing, 63-74. 
1552

Škerlavaj, M., Štemberger, M. I., Škrinjar, R., \& Dimovski, V. (2007). Organizational learning culture-the missing link between business process change and organizational performance. International Journal of Production Economics, 106(2), 346-367.

Teo, H. H., Wang, X., Wei, K. K., Sia, C. L., \& Lee, M. K. (2006). Organizational learning capacity and attitude toward complex technological innovations: an empirical study. Journal of the American Society for Information Science and Technology, 57(2), 264-279. 